\title{
Study of the unit structure in frequency selective fabric fabricated by u-shaped velvet
}

\begin{abstract}
In this study, the three-dimension (3D) frequency selective fabrics (FSFs) fabricated by U-shaped velvet, using copper wires or silver filaments as the conductive unit material, were prepared. Specimens with different unit structure parameters were experimented and analyzed. Compared to FSFs with dipole unit structure, the velvet fabrics with the same unit length have two resonance peaks in the test frequency range. With an increase of inclination angle of velvet, the resonance frequency is changed slightly, accompanied by a trend of decreasing first and then stabilizing. And the resonance frequency of the FSF would shift slowly to higher frequency under the condition of increasing the linear density of conductive ply yarns. If the total length of $\mathrm{U}$-shaped unit on the bottom is greater, the resonance frequency will go to the lower one. If the total length of $U$-shaped unit is same, specimens with the different number of unit will have the similar resonance frequencies. This work shows that the unit structure of U-shaped velvet FSFs can be designed with more parameters comparing with planar FSF.
\end{abstract}

Keywords: unit structure parameters, 3d structure, u-shaped velvet, frequency selective fabric, metal aperture, electromagnetic materials, electromagnetic function, specific resonance frequency, weft knitting, weaving process, transverse electric wave, ink-jet printing, chemical plating, screen printing, u-shaped connective conditions
Volume I Issue 4 - 2017

\author{
Yajing Wang, ${ }^{1,2}$ Hong Xiao, ${ }^{2}$ Huanhuan \\ Cheng,' Meiwu Shi, ${ }^{2}$ Qun Wang, ${ }^{3}$ Zhanghong \\ Tang ${ }^{3}$ \\ 'College of Textiles, Donghua University, China \\ ${ }^{2}$ The Quartermaster Equipment Research Institute of Logistical \\ Support Department, China \\ ${ }^{3}$ College of Material, Beijing University of Technology, China
}

Correspondence: Yajing Wang, College of Textiles, Donghua University, Shanghai, China, Email I I57268536@qq.com

Received: March 28, 2017| Published: April 18, 2017
Abbreviations: FSS, frequency selective surface; FSF, frequency selective fabric; 3D, three-dimension; 2D, two-dimension

\section{Introduction}

Frequency selective surface (FSS) is a periodic structure with one-dimensional or two-dimension (2D) array. The traditional FSS unit structure is a metal patch or metal aperture. With metal patch structure, FSSs would reflect the electromagnetic wave in the vicinity of the resonance frequency. The metal aperture-type FSSs transmit the electromagnetic wave around the resonance frequency. ${ }^{1}$ In recent years, the FSSs have been investigated by many researchers about the structure of single-layer,,$^{2,3}$ multi-layer ${ }^{4-7}$ or $3 \mathrm{D}^{8-10}$ metal unit. Changing the design of electromagnetic materials, unit size, arrangement and other parameters, metal FSSs can obtain the specific resonance frequency, such as broadband, multi frequency, better angle stability, miniaturization or other characteristics.

Combined with the FSS, the conductive fiber is used as the structural material, and the flexible FSF with electromagnetic function is manufactured by means of textile processing. This research not only has an important scientific significance, but also has an practical value in the field of radar absorbing material, communication window, fabric antenna, flexible functional clothing and so on. ${ }^{11,12}$ At present, domestic and foreign researchers have studied 2D FSF by screen printing, ${ }^{13,14}$ weaving, ${ }^{15}$ weft knitting, ${ }^{16,17}$ embroidery, ${ }^{18,19}$ selective chemical plating, ${ }^{20}$ ink-jet printing ${ }^{21}$ or other textile processing.

In this paper, we propose a novel FSF with 3D U-shaped velvet structure. Compared with the planar FSS, the U-shaped velvet FSF has a 3D design, which increases design parameters. The velvet FSF would have more flexible lightweight characteristics and more structure patterns, which a conventional FSS does not have. ${ }^{12,22}$
As members of our research group, ${ }^{23}$ proposed the U-shaped velvet FSS textiles, which are made by the technology of tufted carpet weaving. The parameter design of electromagnetic functional fabric can be divided into four parts, including the yarn material, the unit shape, the grid array and the electromagnetic wave incidence condition. In the unit design part, ${ }^{22}$ have already explored the influence of the velvet height, the unit cell size, the bottom connectivity on frequency response characteristics. In this study, the structure parameters of other unit design, such as planar and 3D shape, the linear density of the conductive ply yarn, the inclination angle of velvet and different U-shaped connective conditions, are continued to be studied.

\section{Experiment}

\section{FSF specimens with the unit structure of planar dipole and 3D U shape}

U-shaped structure unit, made by conductive yarns, is derived by two ending points of the dipole unit extending along the space Z-direction, which is a kind of $3 \mathrm{D}$ structure. The specimen based on the unit structure of planar dipole is showed in Figure 1. And the specimen with U-shaped unit structure is showed in Figure 2. In the actual production process, FSFs of the U-shaped structure can be woven by the tufted carpet loom.

2D dipole and 3D U-shaped FSF samples were manufactured by using 2 strands of copper wire (the diameter of single strand is 0.1 $\mathrm{mm}$ ) as structure unit, shown in (Figure 1) (Figure 2) respectively. And sample substrate was common cardboards. Of course, non-conductive fabric also can be used as substrate. Experiments of different unit length of dipole and $U$ type periodic structure model were prepared to explore the frequency response difference. The specific parameters of FSF specimens are listed in Table 1. 


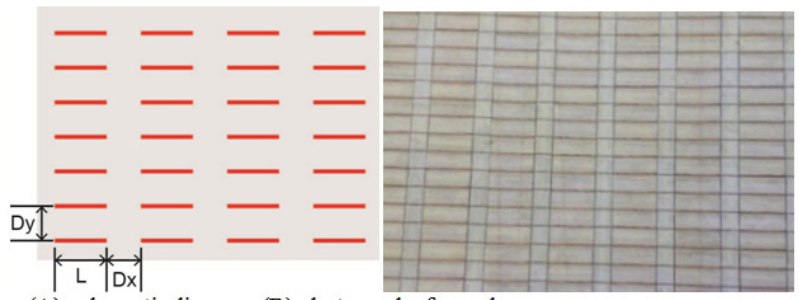

(A) schematic diagram (B) photograph of sample

Figure I Samples with planar structure unit.

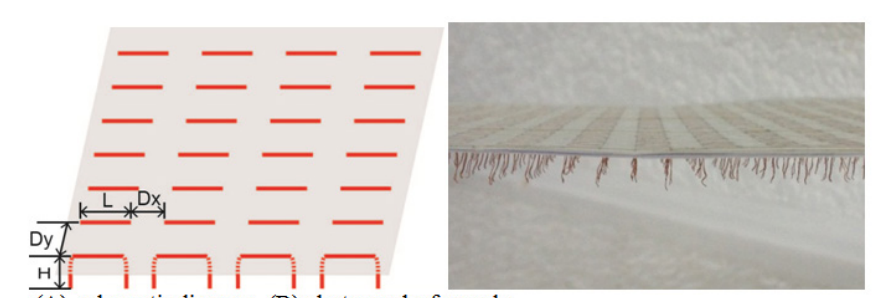

(A) schematic diagram (B) photograph of sample

Table I Sample parameters based on the model of copper wire

Figure 2 Samples with U-shaped structure unit.

\begin{tabular}{llllll}
\hline S. No. & Unit cell length $\mathbf{L}(\mathbf{m m})$ & Spacing $\mathbf{D x}=\mathbf{D y}(\mathbf{m m})$ & Velvet height $\mathbf{H}(\mathbf{m m})$ & Unit cell structure & Velvet material \\
\hline Cu-LI-\# & 6 & 6 & 0 & dipole & Copper wire \\
Cu-L2-\# & 9 & 6 & 0 & dipole & Copper wire \\
Cu-L3-\# & 12 & 6 & 0 & dipole & Copper wire \\
Cu-UI-\# & 6 & 6 & 6 & Independent U type & Copper wire \\
Cu-U2-\# & 9 & 6 & 6 & Independent U type & Copper wire \\
Cu-U3-\# & 12 & 6 & 6 & Independent U type & Copper wire \\
\hline
\end{tabular}

U-shaped velvet FSF specimens with different linear weaving process.

\section{density of silver filaments in the unit structure}

For independent U-shaped FSFs, a research on the linear density of silver filaments has been carried out, where the assembling number of yarns indicates the linear density of conductive yarns. Meanwhile, it determines the amount of conductive yarns in the actual weaving. The conductive yarn linear density is a significant parameter in FSF

Table 2 Sample parameters based on different number of silver filaments
Silver filaments, the single yarn fineness of 10 tex, were used to build up $U$ type FSF. The FSF specimens have the same unit size and different assembling number of silver filaments, including 4, 16 and 28yarns (corresponding to 408dtex, 1630dtex and 2852dtex respectively), as shown in Table 2. The substrate layers are polyester fabric and cellular PE plates, supporting conductive yarns to prevent collapsing, as shown in Figure 3.

\begin{tabular}{lllllllll}
\hline No. & $\begin{array}{l}\text { Unit cell } \\
\text { length L }(\mathbf{m m})\end{array}$ & $\begin{array}{l}\text { Spacing } \\
\mathbf{D y}(\mathbf{m m})\end{array}$ & $\begin{array}{l}\text { Spacing } \\
\mathbf{D x}(\mathbf{m m})\end{array}$ & $\begin{array}{l}\text { Velvet height } \\
\mathbf{H}(\mathbf{m m})\end{array}$ & $\begin{array}{l}\text { Unit Cell } \\
\text { Structure }\end{array}$ & $\begin{array}{l}\text { Velvet } \\
\text { material }\end{array}$ & $\begin{array}{l}\text { Assembling } \\
\text { number of } \\
\text { filaments }\end{array}$ & $\begin{array}{l}\text { Linear density of } \\
\text { filaments }(\mathbf{d t e x})\end{array}$ \\
\hline Ag-DI-\# & 9 & 6 & 6 & 9 & $\begin{array}{l}\text { Independent U } \\
\text { type }\end{array}$ & $\begin{array}{l}\text { Silver } \\
\text { filament }\end{array}$ & 4 & 408 \\
Ag-D2-\# & 9 & 6 & 6 & 9 & $\begin{array}{l}\text { Independent U } \\
\text { type }\end{array}$ & $\begin{array}{l}\text { Silver } \\
\text { filament }\end{array}$ & 16 & 1630 \\
Ag-D3-\# & 9 & 6 & 6 & 9 & $\begin{array}{l}\text { Independent U } \\
\text { type }\end{array}$ & $\begin{array}{l}\text { Silver } \\
\text { filament }\end{array}$ & 28 & 2852 \\
\hline
\end{tabular}

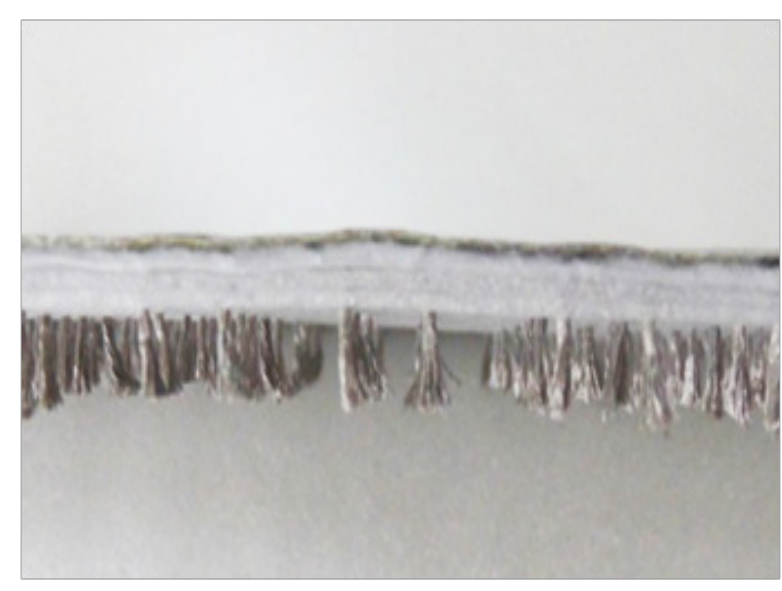

Figure 3 Photograph of sample with substrate layers.
U-shaped velvet FSF specimens with different inclination angles of velvet

Velvet inclination is a very common phenomenon for velvet fabrics. Therefore, the velvet inclination plays an important role in this design. In the process of samples preparation, we need take 1 or 2 layers cellular PE plates ( $1 \mathrm{~mm}$ thick per layer) of sample Ag-D2-\# in Table 2, and then pull cellular PE plates along the extension direction of length $\mathrm{L}$ from the outside to the inside in turn. The purpose is to make different velvet inclination angles $\theta$ (such as $\theta_{0}=0^{\circ}, \theta_{1}=15^{\circ}$, $\theta_{2}=40^{\circ}, \theta_{3}=60^{\circ}$ ), which is seen in Figure 4(a) \& (b). Finally, FSF specimens with inclination velvet were prepared. Velvet inclination is closely related to the shape of the carpet, which is of great value.

\section{U-shaped velvet FSF specimens with different connec- tivity conditions}

The unit structure of the above experimental samples is independent 
U type. However, there are a great many different shapes in practice, such as the cube, cylinder and so on. Therefore, it is very necessary to study different connection modes of U-shaped unit structures. Figure 5 indicates that the total length of the unit cell at the bottom is the same, and that the number of $U$ type is different. Another kind of connectivity is continuous unit cells with the same length of single $U$ type and different $U$ type number, as seen in Figure 6.

By adjusting needle distance, velvet higher and other parameters of the machine, U-shaped velvet FSF specimens with different connectivity conditions were produced by the tufted carpet sample loom. Unit structures were formed by silver filaments. Common polyester yarns had a supporting role and substrates were ordinary carpet substrate cloth. The specific parameters are shown in Table 3.

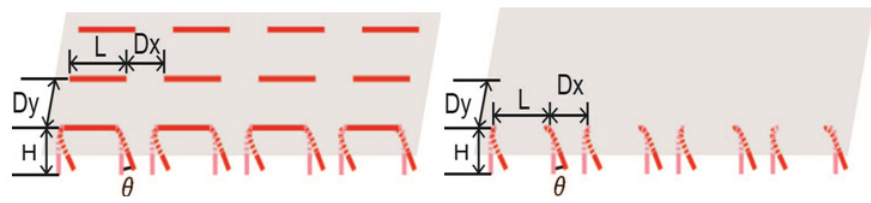

(A)Diagram of the inclination of U-shaped velvet (B) Diagram of the inclination of double-column velvet

Figure 4 Diagram of the inclination of velvet.

\section{U-shaped velvet FSF specimens with different connec- tivity conditions}

The unit structure of the above experimental samples is independent U type. However, there are a great many different shapes in practice, such as the cube, cylinder and so on. Therefore, it is very necessary to study different connection modes of U-shaped unit structures. Figure 5 indicates that the total length of the unit cell at the bottom is the same, and that the number of $U$ type is different. Another kind of connectivity is continuous unit cells with the same length of single $U$ type and different $U$ type number, as seen in Figure 6.

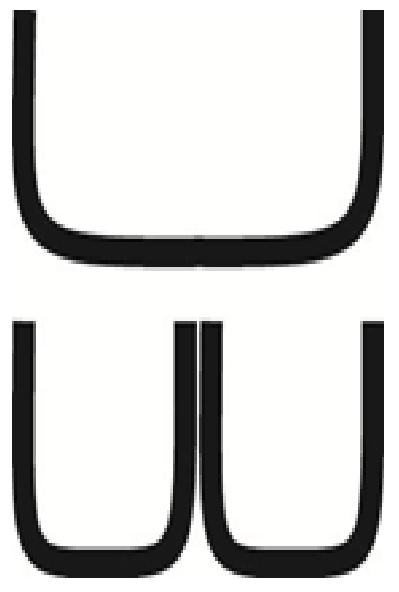

Figure $\mathbf{5}$ The same total length $L$ of the unit cell, the different number of $U$ type.

By adjusting needle distance, velvet higher and other parameters of the machine, U-shaped velvet FSF specimens with different connectivity conditions were produced by the tufted carpet sample loom. Unit structures were formed by silver filaments. Common polyester yarns had a supporting role and substrates were ordinary carpet substrate cloth. The specific parameters are shown in Table 3.

\section{Experimental test}

In this work, the shielding chamber was used to test the transmission coefficient of samples. Testing system included an Agilent E8257D signal generator $(250 \mathrm{KHz}-40 \mathrm{GHz})$, an E7405AEMC spectrum analyzer $(100 \mathrm{~Hz}-26.5 \mathrm{GHz})$, two horn antennas $(1 \mathrm{GHz}-18 \mathrm{GHz})$ and an absorbing screen etc. According to GJB 6190-2008 (Measuring method for shielding effectiveness of electromagnetic shielding materials), environmental conditions, transmitting and receiving antenna position were set up. The sample transmission coefficient of $1-18 \mathrm{GHz}$ was tested by transverse electric wave. Figure 7 is diagram of the testing system, where the center of the transmitting antenna, the testing samples and the receiving antenna were located on the same horizontal line. And the testing sample size was $18 \mathrm{~cm} \times 18 \mathrm{~cm}$.

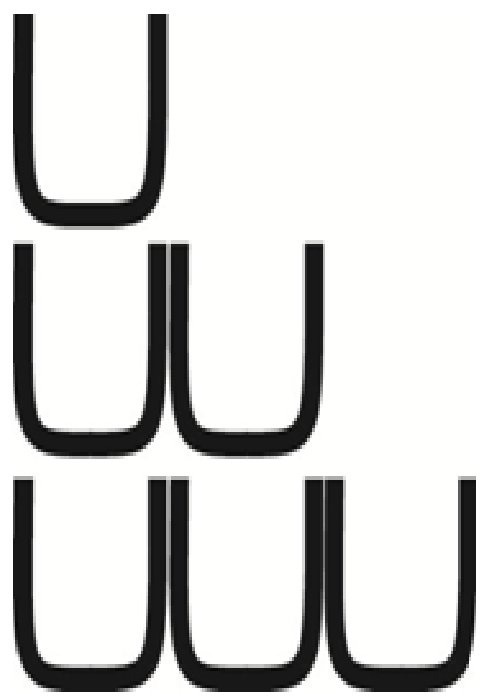

Figure 6 Continuous unit cell with the same length of single $U$ type and different $U$ type number.

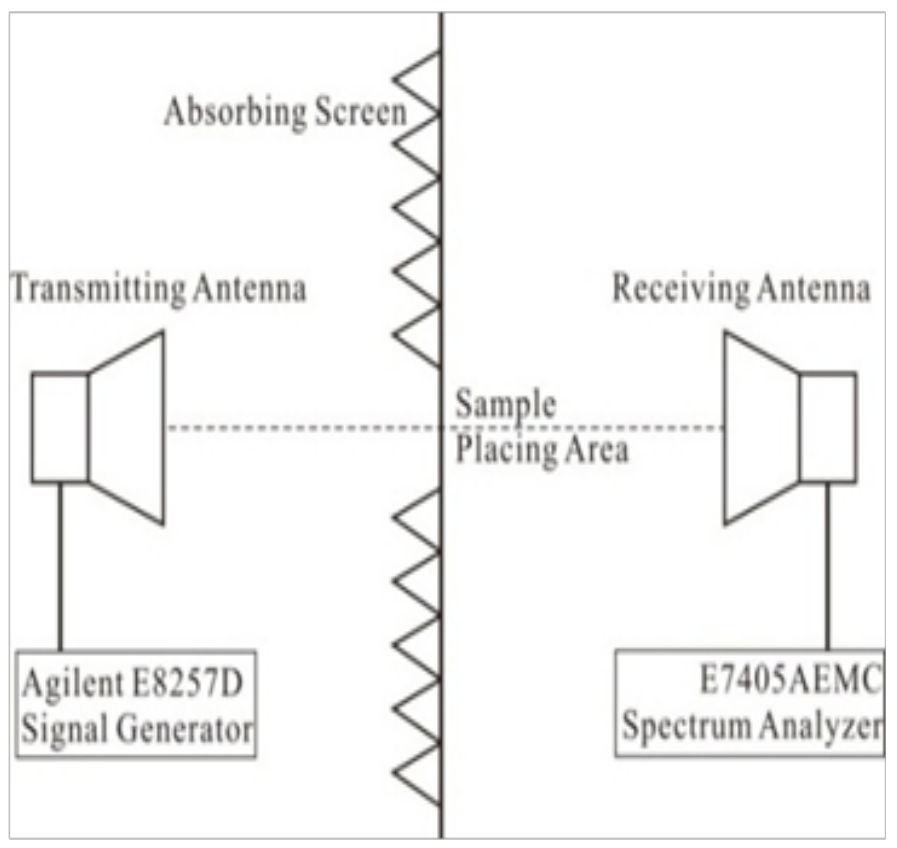

Figure 7 Diagram of the testing system for transmission coefficient. 
Table 3 Sample parameters based on different U-shaped connectivity conditions

\begin{tabular}{|c|c|c|c|c|c|c|}
\hline No. & $\begin{array}{l}\text { Unit cell length } \\
\text { L(mm) }\end{array}$ & $\begin{array}{l}\text { Spacing } \\
\text { Dx=Dy }(\mathrm{mm})\end{array}$ & $\begin{array}{l}\text { Velvet height } \\
\mathrm{H}(\mathrm{mm})\end{array}$ & $\begin{array}{l}\text { Unit cell } \\
\text { structure }\end{array}$ & Velvet material & $\begin{array}{l}\text { Linear density of } \\
\text { filaments(dtex) }\end{array}$ \\
\hline Ag-IU-\# & 6 & 6 & 9 & Independent U & Silver filament & 1630 \\
\hline Ag-2U-\# & 12 & 6 & 9 & Double U & Silver filament & 1630 \\
\hline Ag-3U-\# & 18 & 6 & 9 & Three U & Silver filament & 1630 \\
\hline Ag-U-I\# & 12 & 6 & 9 & Independent $U$ & Silver filament & 1630 \\
\hline
\end{tabular}

\section{Results and analysis}

Comparison of frequency response characteristics of the 3D U-shaped velvet FSF and planar dipole cell structure FSF

The $\mathrm{Cu}$-L series samples, with different unit length of $6 \mathrm{~mm}, 9 \mathrm{~mm}$ and $12 \mathrm{~mm}$, were the planar dipole FSFs and the velvet high $\mathrm{H}$ of samples was $0 \mathrm{~mm}$. As contrast, the velvet high of the $\mathrm{Cu}-\mathrm{U}$ series samples was $6 \mathrm{~mm}$ and they had the same unit length of $6 \mathrm{~mm}, 9 \mathrm{~mm}$ and $12 \mathrm{~mm}$. In addition, the other parameters were the same. The test results are shown in Figure 8.

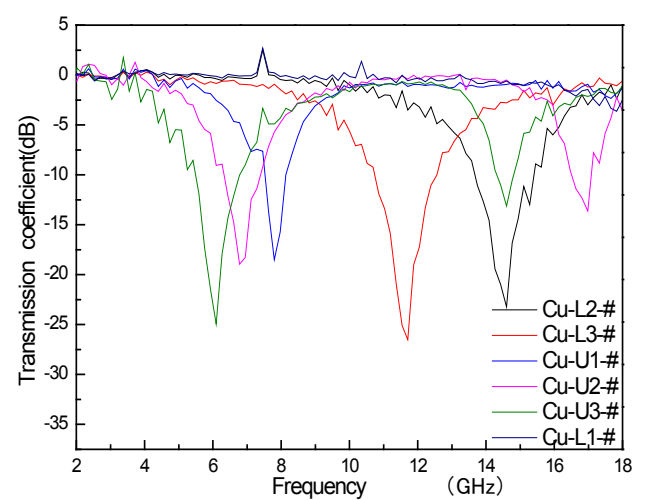

Figure 8 Comparison of frequency response characteristics of 2D and 3D periodic structure samples.

As it can be seen in Figure 8, the transmission coefficient of specimens at 2-18GH were tested. The unit structure of 2D FSF is the planar dipole and 3D FSF structure is U type. With the same bottom unit length $\mathrm{L}$ of $6 \mathrm{~mm}$, the planar sample $\mathrm{Cu}-\mathrm{L} 1-\#$ does not produce resonance in the $2-18 \mathrm{GHz}$ band, while sample $\mathrm{Cu}-\mathrm{U} 1-\#$ with the independent $\mathrm{U}$ type structure generates the resonance at $8 \mathrm{GHz}$. When unit length $\mathrm{L}$ is $12 \mathrm{~mm}$, the resonance frequency of $2 \mathrm{D} \mathrm{FSF}(\mathrm{Cu}-\mathrm{L} 2-\#)$ is $14.6 \mathrm{GHz}$ and $3 \mathrm{D} \mathrm{FSF}(\mathrm{Cu}-\mathrm{U} 2-\#)$ has two resonance points, which are $6.8 \mathrm{GHz}$ and $17 \mathrm{GHz}$. 2D FSF(Cu-L3-\#) with the unit length of $18 \mathrm{~mm}$ resonates at $11.7 \mathrm{GHz}$ and $3 \mathrm{D} \mathrm{FSF}(\mathrm{Cu}-\mathrm{U} 3-\#)$ resonates at $6.1 \mathrm{GHz}$ and $14.6 \mathrm{GHz}$. These can be concluded as follows:

A. The 3D U-shaped velvet FSF, which is extended from the direction of the dipole height, has a dual-band effect.

B. When the resonance points are the same (e.g.14.6GHz), samples may be composed of different unit cell structures.

C. The resonance frequency of 2D FSF, whose parameters are the same as the $3 \mathrm{D}$ except the high $\mathrm{H}$ (e.g. $\mathrm{H}=0 \mathrm{~mm}$ and $\mathrm{H}=6 \mathrm{~mm}$ ), is between the two resonance frequency of the 3D FSF and slightly closer to the larger resonance frequency of the 3D FSF.

\section{The influence of the velvet assembling number}

The linear density of yarns is an important design parameter of FSF. In this study, the velvet linear density is represented by the assembling number of silver filament. The assembling number of conductive yarns in the unit structure of the sample Ag-D series was 4, 16 and 28 respectively, and corresponding yarn linear density was $408 \mathrm{dtex}$, $1630 \mathrm{dtex}$, and $2852 \mathrm{dtex}$. Test results of transmission coefficient are shown in Figure 9. The resonance frequency of the samples varies from $5.25 \mathrm{GHz}$ to $5.83 \mathrm{GHz}$. With an increase of the conductive yarn linear density, the distance between the units and the unit coupling capacitance decrease. As a result, the resonance frequency is increased slowly. Because of increasing velvet linear density, the gap between velvet may affect the frequency response characteristics.

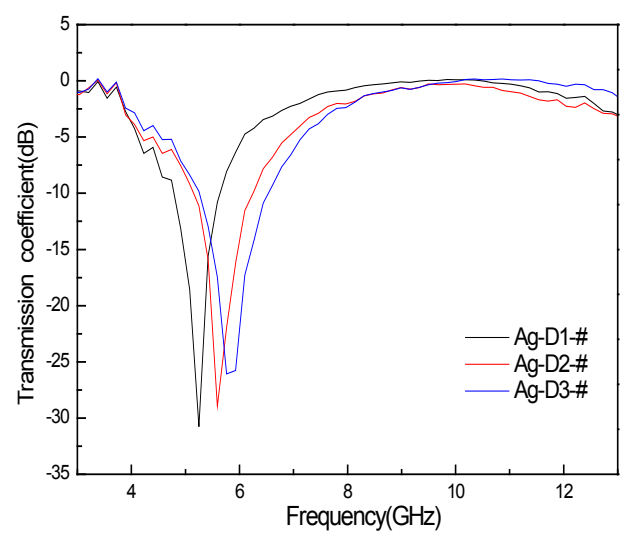

Figure 9 Transmission coefficient of samples with different linear density.

\section{The influence of the inclination angle of velvet}

Qualitative study of velvet inclination is investigated, namely this is to explore the impact of different velvet inclination angle on transmission coefficient. In the experiment, the sample Ag-D2-\# was prepared with silver filaments of 16 assembling number. The inclination angle $\theta$ of velvet is shown in Figure 4(a), where $\theta_{0}, \theta_{1}$, $\theta_{2}$ and $\theta_{3}$ are $0^{\circ}, 15^{\circ}, 40^{\circ}$ and $60^{\circ}$ respectively). The double-column model is obtained by cutting the dipole of $U$ type, as shown in Figure 4(b). Experimental results are shown in Figure 10.

In Figure 10(a), the sample has a $U$ type unit and the resonance frequency is in the range $5.25-5.76 \mathrm{GHz}$. In Figure 10(b), the transmission coefficient of the sample with a double-column type unit is about $0 \mathrm{~dB}$. The analysis is as follows.

Velvet inclination angle $\boldsymbol{\theta}$ : Cheng et al. ${ }^{22}$ analyzed that the resonance point moved to the lower frequency with an increase of the velvet height or the unit length $\mathrm{L} .{ }^{22}$ However, the increase of velvet inclination angle $\theta$ leads to two results, the equivalent height of the unit decreasing 
and the velvet equivalent length in the electric field increases. When $\theta$ is less than a certain angle, the impact of the equivalent height on the resonance frequency is less than the impact of the velvet equivalent length. Thus, resonance frequency moves to the low frequency. When $\theta$ is greater than a certain angle; the resonance frequency maintains a certain value. As a whole, the resonance frequency has decreased gradually and then held the resonance frequency nearby a constant value during the inclination angle $\theta$ increasing.
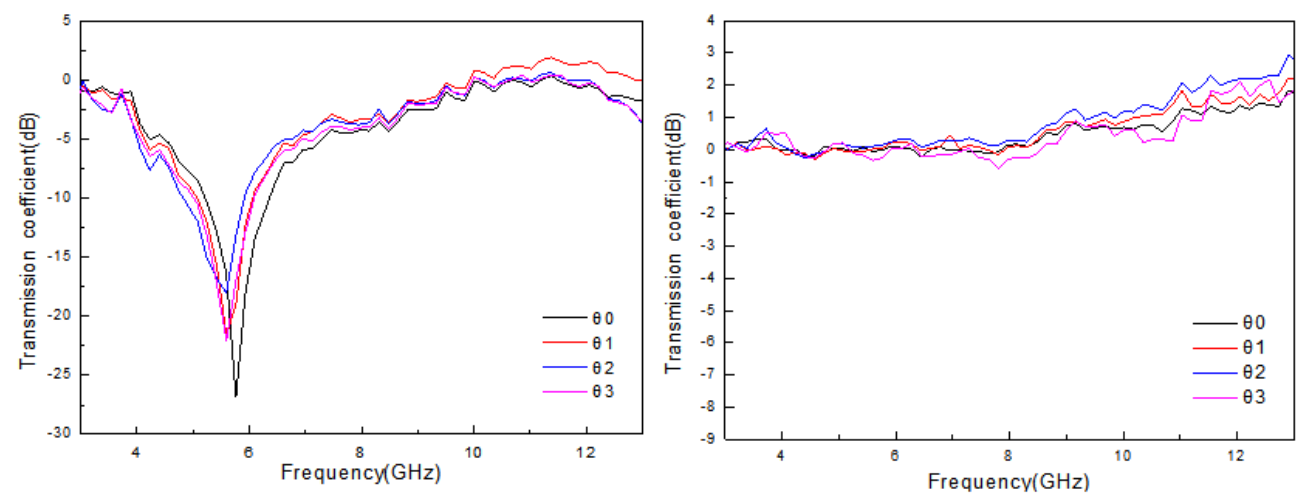

(A) Unit structure with U type (B) Unit structure with double-column type

Figure 10 Transmission coefficient results of sample Ag-D2-\#with different inclination angle of velvet.

Double-column structure: The transmission coefficients of doublecolumn structure unit samples with different angles remain unchanged, indicating that the influencing factor of the resonance frequency is mainly the U-shaped structure at the bottom, instead of a separate double-column structure. The U type structure is commonly applied to velvet carpet products. Ordinary non-conductive yarns are used to support and fix the unit cell structure made by the conductive yarns in FSF samples. And compact velvet arrangement can effectively solve the problem of velvet inclination.

\section{The influence of $U$-shaped connective conditions on the bottom}

The same total length $L$ of the unit cell, the different number of U type: Generally, a U type, woven by the tufted carpet loom, is far less than $9 \mathrm{~mm}$. Hence, we need explore the impact of the number of $U$ type under the condition of the same total length $L$ of the unit, which determines whether samples with different cell shapes are manufactured by the tufted carpet sample loom or not. When the unit total length $\mathrm{L}$ of the bottom was $12 \mathrm{~mm}$, the sample of single- $\mathrm{U}$ type Ag-U-1\# and the sample of double-U type Ag-2U-\# were produced respectively, as seen in Figure 5. And testing results for the transmission coefficient are shown in Figure 11. The resonance point of the single-U type sample with the bottom length $\mathrm{L}$ of $12 \mathrm{~mm}$ is $11.8 \mathrm{GHz}$. The resonance point of the double-U type sample with the same parameters is $12 \mathrm{GHz}$. From the experimental data, we can obtain that if the unit total length $\mathrm{L}$ is a constant value, the number of $\mathrm{U}$ connected elements will hardly affect the resonance frequency. That is to say, the effective unit length L of the FSS is the total length in contact with the U type. According to this characteristic, FSFs with different unit shapes, which are made up of many small U types, can be woven by the tufted carpet loom. The slight movement of the curve in the figure is related to the error of the system and the gap of arrangement.

The same length of single $U$, the different number of $U$ type: The single-U length was $6 \mathrm{~mm}$. With the increase of the number of connected $\mathrm{U}$ type, the sample Ag-1U-\#, Ag-2U-\#, Ag-3U-\#, whose unit length were $6 \mathrm{~mm}, 12 \mathrm{~mm}$ and $18 \mathrm{~mm}$ respectively, were made. The transmission coefficient curve is studied, and the test results are shown in Figure 12. In the graph, the first resonance frequency of the three curves is around $5 \mathrm{GHz}$, and the second resonance point is in
$10-14 \mathrm{GHz}$. The more the number of connected $U$ type is, the smaller the resonance frequency results. Due to the increase of the U-shaped number, the unit total length of the bottom is longer, which is easy to resonate at lower frequency.

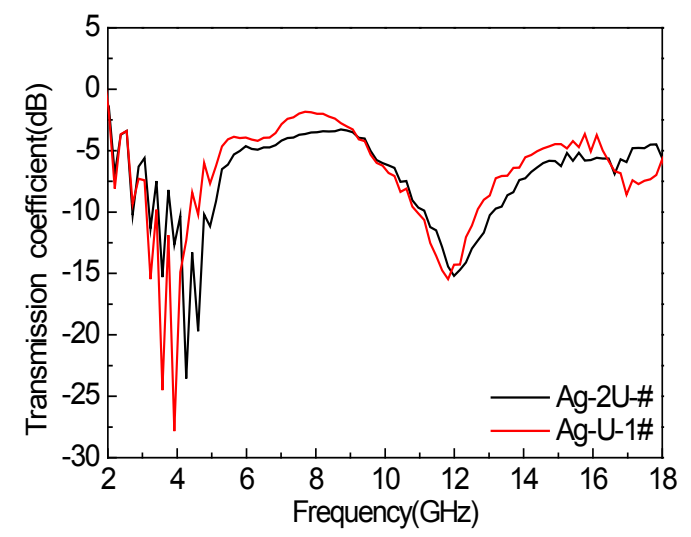

Figure I ITransmission coefficient of samples with different $U$ number and same unit total length.

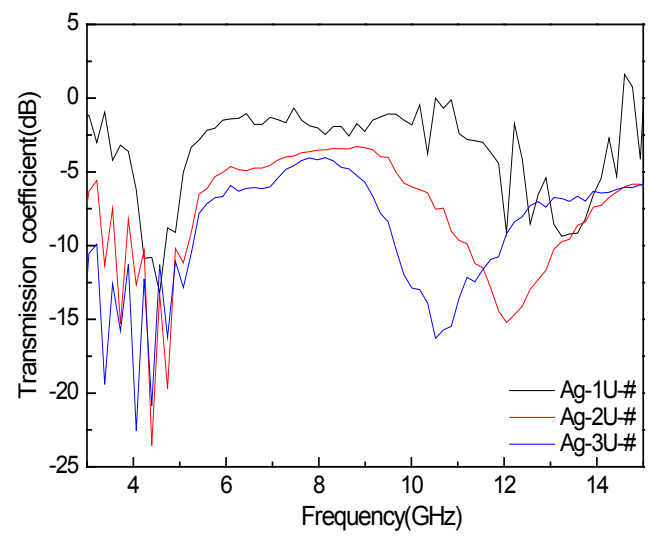

Figure 12 Transmission coefficient of samples with different $U$ number. 


\section{Conclusion}

In our work, 2D and 3D samples with the same bottom unit length $\mathrm{L}$ and $3 \mathrm{D}$ samples with different parameters were prepared. Conclusions are drawn as follows:

A. The 3D FSFs have the double-frequency resonance.

B. With an increase of the linear density of conductive yarns, the resonance frequency moves to higher frequency.

C. As inclination angle $\theta$ of velvet is larger, the resonance frequency has a trend of decreasing first and then stabilizing.

D. The number of connected $U$ type rarely affects the resonance frequency of samples with the same bottom length $\mathrm{L}$.

E. When the single-U length is the same, the more the number of connected $\mathrm{U}$ type is, the lower the resonance frequency results.

Based on the characteristics of lightweight, soft and flexible, the velvet fabric with FSS has a variety of design in aspects of materials, unit sizes and shapes and others. According to the above experimental results, it will be easier to develop the products with specific resonance points. Besides, a large number of experiments are still.

\section{Acknowledgments}

None.

\section{Conflict of interest}

Author declares there is no conflict of interest in publishing the article.

\section{References}

1. Yücel B. Journal of Alloys and Compounds. 2008;458:271-276.

2. Whittow WG, Li Y, Torah R. Printed frequency selective surfaces on textiles. Electronics Letters. 2014;50(13):916-917.

3. Lee C, Sainati R, Franklin R. Comparative analysis of frequency selective surface geometry effect in Fabry-Perot Cavity antenna design. Wireless and Microwave Technology Conference (WAMICON) IEEE 16th Annual. 2015. p. 1-4.

4. Ebrahimi A, Nirantar S, Withayachumnankul W. Terahertz band pass frequency selective surface with improved out-of-band response. Infrared, Millimeter, and Terahertz waves (IRMMW-THz), 40th International Conference. 2015. p. 1-2.

5. Yan M, Qu S, Wang J. Broadband band-pass FSS using patch-wire-patch coupled structures. Advanced Materials and Processes for RF and THz Applications (IMWS-AMP), IEEE MTT-S International Microwave Workshop Series. 2015. p. 1-3.

6. Chatterjee A, Mandal B, Biswas J. A dual-layer reflective Frequency Selective Surface for wideband applications. Computing and Communication (IEMCON), International Conference and Workshop. 2015. p. 1-3.

7. Liang B, Miao J, Bai M. A novel dual-layer frequency selective surface with grating lobes suppression. Antennas and Propagation \& USNC/ URSI National Radio Science Meeting, IEEE International Symposium. 2015. p. 1274-1275.
8. Sanz Izquierdo B, Parker EA. Frequency selective surfaces formed by partially metalising 3D printed shapes. Antennas and Propagation (EuCAP), 9th European Conference. 2015. p. 1-4.

9. Sanz Izquierdo B, Parker EA. 3D printed FSS arrays for long wavelength applications. Antennas and Propagation (EuCAP), 8th European Conference. 2014. p. 2382-2386.

10. Barton JH, Garcia CR, Berry EA. All-dielectric frequency selective surface for high power microwaves. IEEE Transactions on Antennas and Propagation. 2014;62(7):3652-3656.

11. Xu XX, Wang Q, Tang ZH. Application of Frequency Selective Surface Textile Material. Safety and Electromagnetic Compatibility. 2015;(2):55-58.

12. Cavalcante GA, D Assunção AG. An iterative Full $\square$ wave Method for Designing Band stop Frequency Selective Surfaces on Textile Substrates. Microwave and Optical Technology Letters. 2014;56(2):383-388.

13. Guan FW, Shi MW. Fabrication Method and Application Research of Frequency Selective Fabric (FSF). The 89th Textile Institute World Conference. Wuhan Textile University, China; 2014. p. 1015-1019.

14. Guan FW, Xiao H, Shi M, et al. The Novel Frequency Selective Fabric and Application Research. J Industrial Textiles. 2015;11(9):1-17.

15. Seager RD, Chauraya A, Bowman J. Fabric Based Frequency Selective Surfaces Using Weaving and Screen Printing. Electronics Letters. 2013;49(24):1507-1509.

16. Tennant A, Hurley W, Dias T. Experimental Knitted, Textile Frequency Selective Surfaces. Electronics letters. 2012;48(22):1386-1388.

17. Tennant A, Hurley W, Dias T Knitted, Textile, High Impedance Surface with Integrated Conducting Vias. Electronics Letters. 2013;49(1):8-10.

18. Chauraya A, Seager R, Whittow W. Embroidered Frequency Selective Surfaces on Textiles for Wearable Applications. Antennas and Propagation Conference (LAPC). 2013. p. 388-391.

19. Lv ZM, Tang ZH, Xu XX. Preparation and Transmission Characteristics of Flexible Frequency Selective Surfaces. Safety and Electromagnetic. 2014;4:79-81.

20. Chauraya A, Whittow WG, Vardaxoglou JC. Inkjet Printed Dipole Antennas on Textiles for Wearable Communications. IET Microwaves, Antennas \& Propagation. 2013;7(9):760-767.

21. Whittow WG, Chauraya A, Vardaxoglou JC. Inkjet-printed Micro strip Patch Antennas Realized on Textile for Wearable Applications. IEEE Antennas and Wireless Propagation Letters. 2014;13:71-74.

22. Cheng HH, Xiao H, Shi M, et al. Research on 3D periodic structure velvet fabric and its frequency response characteristics. Textile Research $J$. 2015;86(7):776-784.

23. Xiao H, Shi MW, Wang Q, et al. The electromagnetic shielding and reflective properties of electromagnetic textiles with pores, planar periodic units and space structures. Text Res J. 2014;84(16):1679-1691. 